\title{
A INTERPRETAÇÃO JUDICIAL E SUA RELAÇÃO COM O PAPEL DA AVALIAÇÃO LEGISLATIVA
}

\section{THE JUDICIAL INTERPRETATION AND ITS RELATIONSHIP WITH THE ROLE OF LEGISLATIVE REVIEW}

\author{
Viviane Freitas Perdigão Lima ${ }^{1}$
}

\section{RESUMO}

O presente estudo faz reflexão sobre a avaliação legislativa no Brasil e a carente participação da Universidade na construção das leis, resultando em um dos fatores que também desencadeiam a interferência dos Tribunais na concretização dos valores e fins constitucionais: o ativismo judicial. Procurar-se-á, com o intuito de ilustrar essa correlação, colher da atividade legislativa, no caso dos projetos de lei sobre desaposentação, a falta do uso de métodos, técnicas e estudos na construção da referida lei, o que posterga a concretização da mesma, resultando na jurisprudência pacifica do Superior Tribunal de Justiça a respeito do tema.

Palavras-chave: Avaliação Legislativa. Universidade. Ativismo Judicial.

\begin{abstract}
This study is reflection on legislative evaluation in Brazil and lacking participation of the University in the construction of laws, resulting in one of the factors that also trigger the interference of the courts in pursuit of values and constitutional purposes: judicial activism. Search It will, in order to illustrate this correlation, spoon legislative activity in the case of law desaposentação projects, the lack of use of methods, techniques and studies on the construction of that law, which postpones the implementation of same, resulting in the peaceful jurisprudence of the Superior Court of Justice on the subject.
\end{abstract}

Keywords: Legislative review. University. Judicial Activism.

1 Advogada. Mestre em Direito pelo programa Direito e Instituições do Sistema de Justiça da Universidade Federal do Maranhão - UFMA, São Luís, (Brasil). Professora substituta do curso de Direito da Universidade Estadual do Maranhão (UEMA). E-mail: viperdigao@gmail.com 


\section{INTRODUÇÃO}

Objetiva-se analisar a importância de uma avaliação legislativa, com uso de técnicas, métodos e participação das Universidades na construção das leis, como um fator não propulsor do ativismo judicial. Compreende-se que nos Estados democráticos, existe uma parcela de poder político para ser exercido pelo Judiciário. Em verdade, são agentes políticos que não são eleitos. Entretanto, quando os órgãos judiciais resolvem conflitos entre particulares, determinando, por exemplo, o pagamento de uma indenização por quem causou um acidente, punindo um homicida, resolvendo um divórcio. Não há que se falar em polêmica sobre a legitimidade do poder que exerce. Isto porque estão agindo conforme determinada lei.

Assim, visa-se demonstrar que em tais modelos democráticos, a Constituição Federal confere a ele competência para solucionar os litígios em geral. Contudo, a questão ganha em muita complexidade quando o Judiciário atua em disputas que envolvem a validade de atos estatais ou nas quais o Estado, como outros órgãos de Poder, seja parte. É o que ocorre quando declara o direito de greve dos servidores públicos, por exemplo, ou, determina a um hospital público que realize tratamento experimental em paciente que solicitou tal providência em juízo. Mas algo que tem chamado atenção dos juízes, no contexto atual, é deferir pedido de desaposentação, mesmo não havendo em tal caso qualquer lei expressa do Congresso Nacional ou Decreto Presidencial que autorize a medida.

Verifica-se a atuação do judiciário para fatos ocorridos ou na iminência de ocorrer. Entretanto, nota-se que para atuação para o futuro, acerca do processo criativo das leis, suas expectativas, consequências sociais, econômicas, debates, avaliações, todo estes mecanismos ainda são tímidos no Brasil. A par disso, percebe-se, no presente artigo, íntima relação dessa carência, no âmbito do Poder legislativo, como fator propulsor do avanço judicial sobre funções típicas atribuídas com exclusividade aquele órgão.

O escopo do presente estudo busca analisar o ativismo judicial como resultado da carência de aplicação de estudos, métodos e resultados no processo de criação das leis. Por fim, demonstra-se a necessidade de maior participação das Universidades, como centro produtor de conhecimento, na construção do ciclo de vida da lei evitando-se a atuação das funções jurisdicionais em espaços vazios, desencadeadas pelo desempenho deficiente da produção normativa do país.

Adota-se a linha metodológica weberiana, afastando-se das categorias sociológicas macroestruturais e utilizando-se o recurso do tipo ideal, para o compromisso explícito com a 
análise empírica do real. Cabe salientar, é de relevância ímpar que a realidade não possui um sentido intrínseco ou único, visto que são os indivíduos que lhe conferem significados.

Como elemento de importância a ser ressaltado, buscou-se a análise dos projetos de lei da desaposentação diretamente no endereço virtual das duas casas legislativas federais. Sobre a Lei Complementar citada no trabalho, fez-se a pesquisa diretamente no sítio eletrônico do Governo Federal sem passar por pesquisa doutrinaria a respeito do tema. Quanto à busca realizada no endereço eletrônico da Assembleia Legislativa do Maranhão, também se utilizou dos mesmos mecanismos das analises acima.

O presente artigo esta dividido em duas partes. A primeira traz reflexões diretamente traçadas sobre o assunto no Poder Legislativo, sobretudo, no processo criativo das leis. Demonstra-se a importância da participação das Universidades para a criação de um espaço argumentativo democrático; déficit de participação dos acadêmicos do Direito no processo de elaboração normativa; a importância da avaliação legislativa e se há aplicação dessa técnica no projeto da desaposentação. No segundo momento, a discussão concentra-se no Poder Judiciário, o que se entende por ativismo judicial e qual sua relação na produção normativa do Poder Legislativo. Por fim, concluiu-se que na construção de leis, como no caso da desaposentação, deveria haver uma maior reflexão sobre a utilização de métodos, técnicas, demonstrações, participação das Universidades, enfim, passar por um regular processo avaliativo legislativo o que se evitaria a demora na aprovação da mesma, consequentemente, não haveria que se falar em ativismo judicial.

\section{A UNIVERSIDADE E A CONSTRUÇÃO DO PROCESSO LEGISLATIVO}

$\mathrm{Na}$ historia da pesquisa jurídica no Brasil houve maior declinação ao estudo do Direito Positivo em detrimento da análise do processo legislativo. Ao se analisar as diversas produções acadêmicas como artigos e livros publicados na área do Direito percebem-se um olhar para a lei como algo com fim em si mesmo, ou seja, pronto e acabado, deixando-se em segundo plano o seu processo de formação.

Observa-se uma cultura que indica uma falta de reconhecimento do Parlamento como instância legítima para o debate jurídico a qual transfere todo o debate público sobre a formação legislativa para o momento no qual a norma é analisada pelo Judiciário. 
Sendo assim, torna-se comum observar, por exemplo, mais debate sobre a constitucionalidade das leis já promulgadas do que pesquisa e avaliação dos problemas de um projeto de lei que poderia contrariar o texto constitucional se fossem aprovado.

Qualquer visão realista do processo legislativo inclui a influência desses grupos. Tal processo tem implicação direta na relação entre os três Poderes no Brasil, assim como, nos fundamentos da democracia brasileira.

Deve-se superar uma antiga dicotomia entre a Constituição e a democracia. Com isso, evita-se um processo democrático de construção das normas, que, para ser democrático, não precisaria observar regras constitucionais, ou um processo que respeite os estritos limites constitucionais, cabendo à instância maior constitucional o papel de desenvolver a Constituição como inibidora da formação da norma pelo Parlamento.

O Supremo Tribunal Federal, como representante argumentativo da sociedade, deve exercer o controle de constitucionalidade por meio de um diálogo constitucional, a partir de argumentos racionais, com o Parlamento (FISHER, 1988). Tal diálogo só pode ser concretizado se o processo legislativo também for reconhecido como um processo argumentativo racional. A par disso, pode-se enxergar um diálogo entre os Poderes e não apenas um processo de criação normativa por parte do Judiciário.

É notório, que a jurisdição constitucional não deve ser entendida como algo que se sobrepõe ao procedimento legislativo democrático. Deve ser vista como instância que convive com ele e visualiza, em sua análise argumentativa, a presença ou não dos pressupostos de legitimidade da lei produzida.

Percebe-se que deve haver um diálogo constitucional entre os Poderes. Para isso, é necessário que seja criada uma possibilidade de comunicação entre as decisões tomadas pelo Parlamento e as decisões proferidas pelo Poder Judiciário.

É bem percebido por Dworkin (2007) que o percurso para a comunicação democrática e consistente entre os poderes passa pela incorporação do que chama de integridade. Para ele é necessário, em primeiro lugar, assumir que as comunidades políticas democráticas devem ser comunidades de princípios, e não apenas comunidades de interesses ou de regras.

A ideia de integridade, portanto, repagina o conceito de autogoverno. Deve-se evitar uma representação simbólica do povo. A comunidade constituída por princípios, como propõe Dworkin (2007) exige que toda manifestação de poder (e não apenas a legislação) se interligue a estes princípios, assim, transpõe o povo como titular direto deste poder. 
Nesse passo, com a construção de argumentos racionais bem fundamentados, tanto no processo legislativo quanto no exercício do controle de constitucionalidade, que se pode buscar a comunicação entre legislação e adjudication, que resultará na integridade do direito.

Diga-se, desde logo, que é fundamental que as Universidades deixem de olhar apenas para a norma vigente e perceba a importância de uma pesquisa jurídica voltada também para o Legislativo. Com isso, o processo legislativo passará a ser reconhecido como um espaço argumentativo de construção democrática. Assim, com a participação das Universidades, haverá o fornecendo de argumentos sólidos sobre os quais o diálogo constitucional entre os poderes possa realmente se estabelecer.

Se bem construído o processo legislativo como espaço argumentativo, se evitará a ocupação do Poder Judiciário em instâncias políticas tradicionais, que restaram embaraçadas por mecanismos inadequados de funcionamento e por vícios do instituto de representação. Constatou Garapon (1996, p. 23), que perante a decomposição do politico, "é doravante ao juiz que se pede a salvação. Os juízes são os últimos ocupantes de uma função de autoridadeclerical e até paternal - abandonada pelos seus antigos titulares”.

É dessa tentativa de construção de argumentos sólidos na construção das leis que se almeja a criação de projetos nos diferentes ministérios para estudos de criação de normas; acompanhamento do processo legislativo e a produção de pareceres sobre as proposições legislativas que tramitam no Congresso Nacional. Ao convocar as Universidades para refletir sobre temas em discussão no Legislativo, o que se pretende é contribuir para que se fortaleçam os ambientes argumentativos dentro do Parlamento, evitando-se a ocupação pelo judiciário em espaços vazios.

\subsection{Leis: Mudança do Instrumento Normativo}

Muito se debate que o cumprimento ineficiente das funções reservadas ao Poder Legislativo não resulta apenas de sua capacidade institucional de produzir as normas reclamadas tanto para a concretização da Constituição quanto a regulação social. Mas, sobretudo, da produção excessiva de leis desnecessárias (PEREZ, 2012).

Entretanto, não se trata de exagero ao se afirmar que, nos Estados de Direito de tradição romano-germânica, a lei ainda é peça-chave da engendragem jurídica que os estruturam. Percebe-se que o instrumento normativo, em seus vários perfis, possui papel 
central para a criação do pensamento jurídico, dando-lhe o substrato necessário a aplicação, a interpretação e, até mesmo, eventual revisão das normas vigentes.

A despeito do suposto status privilegiado, observa-se um evidente afastamento da doutrina jurídica da temática relativa à chamada "política legislativa", com déficit de participação dos acadêmicos do Direito no processo de elaboração normativa (OLIVEIRA, 2010, p. 67-75).

Com a maior participação acadêmica no processo elaborativo da norma, se evitará vícios incontestáveis como a fluidez dos programas políticos, que os torna imprestáveis como fortes roteiros pré-fixados da ação governamental. Com o fim de arregimentar o maior numero de eleitores, os partidos políticos elaboram programas genéricos e tanto quanto imprecisos, sem revelar posição ideológica sobre questões essenciais para desencadeá-lo da atividade governamental (PEREZ, 2012).

Existe uma baixa relevância destinada pela Academia à lei deixando em aberto questões que são centrais. "Mais do que isso: não há, de forma densa e rigorosa, preocupação com as alterações que têm atingido os sinais distintivos da lei, nem com o que poderíamos chamar de ciclo de vida do ato normativo". (PAULA; ALMEIDA, 2013, p.25).

Contudo, deve-se ressaltar que a evolução dos Estados contemporâneos trouxe mudanças profundas nas características clássicas do ato normativo. A inflação legislativa e a crescente explosão regulatória, de um lado, e a instrumentalização do ato normativo na estruturação, de outro lado, atingiram alguns elementos tradicionais como a estabilidade, a generalidade, a abstração. (PEREZ, 2012).

Percebe-se, segundo Bucci (2009, p. 29) que "no caso da construção de políticas públicas, por exemplo, existe ganho de espaço da perspectiva na elaboração normativa, em detrimento da análise centrada no direito posto". Entretanto, é grande a ausência do elemento jurídico ou o seu baixo peso nas construções das referidas politicas. Assim como, é baixa a percepção do impacto das políticas públicas para a caracterização da teoria jurídica e do ato normativo.

Trazendo-se em foque mais uma vez para as políticas públicas, percebe-se que é crescente a atenção dispensada às suas características e ao seu ciclo de vida. Existe um pungente desenvolvimento para cada fase: definição de agenda, formulação, implementação e avaliação. Assim como, o alinhamento de padrões claros de trabalho para que se examine eficácia, eficiência e, em especial, sua efetividade. Enfim, há uma série de metodologias e de estratégias, como a avaliação participativa, meta-avaliação, marco lógico, custo/ benefício, 
entre outros, dando ao gestor público e ao acadêmico um ferramental teórico apto a permitir um bom trabalho avaliativo (RUA, 2003).

Contudo, com o instrumento normativo não ocorre o mesmo. É fácil observar que não está no espaço universitário o debate sobre o perfil contemporâneo da lei ou sobre mecanismos de avaliação de sua eficácia, eficiência, assim como, sua efetividade. Sob esta orientação, não estão presentes no discurso jurídico dominante, salvo em referências indiretas sem maior densidade analítica, a preocupação com metas e efeitos legislativos.

\title{
2.2 A avaliação legislativa
}

Segundo Ferreira Filho (2009), afirma-se com segurança que nunca se fizeram tantas leis em tão pouco tempo. Trata a multiplicação das leis como fenômeno universal e inegável, para o autor:

\begin{abstract}
No Brasil, por exemplo, durante todo o império, foram promulgadas cerca de 3.400 leis. Durante a primeira Republica, de 1891 a 1930, cerca de 2.500 leis. E de 18 de setembro de 1946 a 09 de abril de 1964, nada menos que 4.300. e de 1964 ate hoje mais de 7.000 leis. (...) Já medidas provisórias, entre 1988 e a vigência de EC 32/2001, foram promulgadas 619 , com mais de 5.000 reedições (...). (FERREIRA FILHO, 2009, p. 12-13)
\end{abstract}

Noticia L. Mader (2006), que a ciência da legislação, a legística ou a legisprudência e a avaliação legislativa, têm crescido nos últimos tempos, com aparência desigual entre os países. Nos Estados Unidos é a partir dos anos 70 que juristas passam a discutir o desenvolvimento de uma ciência de elaboração de leis. Somente nos anos 80 e 90 que aparecem contornos do desenvolvimento de algumas de suas técnicas e de desenhos institucionais na Europa.

Mais uma vez para L. Mader (2006) a avaliação legislativa encadeia uma serie de análises baseadas no emprego de métodos científicos, no que tange à execução e os efeitos dos atos legislativos. O fim da avaliação legislativa são as relações de causa e efeito entre uma norma legal, por um lado, e uma mudança ou, não mudança de um comportamento, de uma situação ou de uma atitude observável, por outro lado. Objetiva, assim, identificar e apreender os efeitos que a legislação produz sobre a realidade social.

Ensina Haber (2010, p. 111) que "são muitos os métodos, as técnicas e os arranjos institucionais elencados na avaliação legislativa." $\mathrm{Na}$ avaliação prospectiva é possível utilizar métodos como pesquisas legislativas sobre propostas semelhantes, ou ainda a apreciação criteriosa e científica da provável relação custo-benefício de determinada medida; também é possível utilizar mecanismos de teste como simulação, experimentos práticos e, até mesmo, experimentação legislativa (sunset laws). Já na avaliação retrospectiva, categorias similares 
àquelas usadas na avaliação de políticas públicas, por exemplo, são aproveitadas, como a análise de efetividade e a análise do grau de implementação da lei, com consequente empréstimo de ferramentas e metodologias.

A ideia dos estudiosos da área é propor a institucionalização do tema avaliação legislativa. Haber (2011, p. 18) cita que mesmo "em países da Common Law, como EUA e Reino Unido, são pioneiros na adoção de medidas de planejamento e revisão legislativa, ainda na década de 80”. Por exemplo, desde 1995, a Organização para a Cooperação e Desenvolvimento Econômico (OCDE), adota e prescreve um programa de qualidade da produção normativa, baseado em checklist de referência a ser observado antes da tomada de decisões regulatórias.

Existe ainda, o Regulatory Impact Assessment (RIA) ou avaliação de impacto normativo no campo da avaliação legislativa. Trata-se do mais desenvolvido e utilizado mecanismo de avaliação prospectiva de impacto regulatório (HABER, 2011). Refere-se a uma espécie utilizada de forma específica na área econômica, calcada na avaliação custo-benefício ou custo-efetividade de uma norma.

Elenca Haber (2011, p. 131), que "é mais comum verificar uma preocupação com os aspectos formais da lei do que propostas de avaliação de seu conteúdo". Assim, percebe-se que apesar de atual crescimento, no Brasil, ainda é tímida a produção científica e a participação da Universidade a respeito da avaliação legislativa. Na perspectiva acadêmica, a produção restringe-se, majoritariamente, àqueles diretamente envolvidos com o processo legislativo, sobretudo consultores legislativos e servidores de casas parlamentares (MENEGUIM, 2010).

Trazendo-se a baila o caso brasileiro, a Lei Complementar n. ${ }^{\circ}$ 95/98, dispõe sobre elaboração, redação, alteração e consolidação das leis, sob os ditames do paragrafo único art. 59 da Constituição Federal. Já o Decreto n. ${ }^{\circ}$ 4.176, de 28 de março de 2002, criado para regulamentar a referida Lei Complementar, define o encaminhamento ao Presidente da República de projetos de atos normativos de competência dos órgãos do Poder Executivo Federal. (BRASIL, 1998).

Observam-se, quanto aos decretos, projetos de lei e medidas provisórias oriundos do Poder Executivo, houve a intenção de se estabelecer um parâmetro a ser seguido pela avaliação prospectiva ou ex ante, com o objetivo de permitir, ao menos, uma estimativa quanto aos efeitos pretendidos com a alteração normativa. 
Atualmente, as regras da Lei Complementar n. ${ }^{\circ}$ 95, de 1998, e do Decreto n. ${ }^{\circ} 4.176$, de 2002, são utilizadas pelos Ministérios proponentes e pela Subchefia para Assuntos Jurídicos da Casa Civil da Presidência da República para ajustes formais dos atos normativos propostos. Contudo, não se detém quanto ao seu conteúdo material. E mais, a própria LC 95/98 tramitou por nove longos anos no Congresso Nacional e ainda há pontos não efetivados em tal lei. (BARROSO, 2008).

Assim sendo, verifica-se que ainda não se pode derivar da previsão normativa uma prática efetiva ou um programa de avaliação de impacto legislativo. Como exemplo, o preenchimento do anexo II, da referida Lei Complementar apresenta contornos apenas para atender uma exigência burocrática.

No que tange a produção normativa nos Estados, segundo Haber (2011), há algumas iniciativas de Assembleias Legislativas Estaduais que tentam introduzir o tema em seus respectivos Estados.

Em pesquisa na Assembleia Legislativa do Maranhão, ainda não existe estudo sobre avaliação legislativa em seu aspecto material. No site do órgão, digitando-se o termo "elaboração de leis", "avaliação legislativa" no campo pesquisa, nada foi encontrada. Contudo, segundo o Regimento Interno daquela casa (art. 60), as Comissões contarão, para o desempenho das suas atribuições, com assessoramento e consultoria técnico-legislativa e especializada em suas áreas de competências, a cargo do órgão de assessoramento institucional da Assembleia Legislativa, desde que exista iniciativa da Mesa Diretora. (BRASIL, 2014)

A par disso, percebe-se que é ainda tímido, no Brasil, o desenvolvimento de uma ciência de elaboração de leis. Tão pouco, percebe-se a participação da Universidade no debate sobre o emprego de métodos científicos, no que tange à execução e os efeitos dos atos legislativos.

Contudo, sob o foco dos efeitos reais ou potenciais que resultam da aplicação de uma norma, no Legislativo, ainda perpassam por comissões que, por vezes, não verificam elementos factuais que identificação tendências, resultados sociais imprevistos ou indesejáveis, ou mesmo o levantamento de impressões e opiniões dos diversos atores sociais envolvidos na interpretação e aplicação das normas. 


\subsection{A Avaliação Legislativa e o Projeto de Lei da Desaposentação}

Avaliando-se o tema desaposentação, atual como exemplo de conduta proativa do Poder Judiciário, percebe-se que há diversos posicionamentos sobre o tema e aplicação ampla e intensa pelo referido Poder. Contudo, pouco se debate como esta se permeando a avaliação legislativa e a participação das Universidades na construção dos diversos projetos de Lei sobre a desaposentação.

Ibrahim (2011, p. 701) ensina que a desaposentação é definida como a reversão da aposentadoria obtida no Regime Geral da Previdência Social ou mesmo em Regimes Próprios de Previdência de Servidores Públicos, "com o único objetivo de possibilitar a aquisição de um benefício mais vantajoso no mesmo ou em outro regime previdenciário".

No contexto atual, a desaposentação não possui previsão legal expressa, razão pela qual é negada pelos órgãos administrativos, os quais ainda argumentam pela violação do ato jurídico perfeito e do direito adquirido. Nesse sentido, o Instituto do Seguro Social-INSS não vem permitindo tal instituto, pois o Regulamento da Previdência Social (Decreto $n^{\circ}$ 3.048/99) não deu vazão para tal direito. (BRASIL, 1999)

A par disso, cada vez mais surge o conflito entre autarquia federal e trabalhador, na qual o judiciário é chamado a resolver. Contudo, pergunta-se: como esta sendo a apreciação criteriosa e científica da provável relação custo-benefício da desaposentação no projeto de lei? Também é possível utilizar mecanismos de teste como simulação, experimentos práticos e, até mesmo, experimentação legislativa sobre o tema? E os demais setores da sociedade, participam do debate? Audiências Públicas são promovidas? Há participação das Universidades na construção da lei?

Primeiramente, em 2008, o Poder legislativo chegou a aprovar o projeto de lei da desaposentação e consequente alteração na lei federal $n^{\circ}$ 8.213/91. Contudo, foi vetado na íntegra pelo chefe do executivo sob o argumento de vício de iniciativa, implicações sobre servidores públicos e aumento de despesa. (BRASIL, 2008)

Posteriormente e com o surgimento de outros projetos de lei sobre o tema, o Poder Executivo, vendo a propagação divulgou pela primeiravez a despesa que será gerada para os cofres públicos caso o Supremo Tribunal Federal reconheça o direito à desaposentação, requerido hoje por milhares de ações em tramitação nos tribunais brasileiros.

Assim, no âmbito do Executivo, mostra-se mais um debate como tema central o interesse puramente econômico do que um programa de qualidade da produção normativa. 
Não significa que o debate não deva perpassar pelo desenvolvimento econômico. Mas por ele e por outras esferas- tais como vê a gerontologia a desaposentação. Sobretudo, em vista da complexidade da ordem econômica, deve ser chamado os diversos pensamentos e produções cientificas sobre o que desequilibraria o bom crescimento econômico.

Por exemplo, uma boa discursão é a elencada por Sayeg e Balera (2011, p. 177) elencando o Programa das Nações Unidas para o desenvolvimento, os quais relatam: "as pessoas são a verdadeira riqueza das nações. A riqueza de um país não é restrita ao crescimento econômico e ao insuficiente critério de grandeza por meio do calculo do Produto Interno Bruto (PIB)”. Aqui, os autores pugnam pela implementação da filosofia do direito econômico, ou seja, o capitalismo humanista, o que poderia servir de um novo olhar para o Poder Executivo.

Já no Poder Legislativo, com as pressões populares, existem diversos projetos de lei sobre a temática. No Senado Federal existe o PLS 91/2010 do senador Paulo Paim, do Rio Grande do Sul. Na justificativa de tal projeto de Lei, existe a forte necessidade de aprovação em virtude de seu deferimento por outros agentes, tais como o próprio Poder Judiciário e o Tribunal de Contas da União (BRASIL, 2010).

Entretanto, caberia a este Poder usar o instrumento normativo como uma obra criativa e não coadunar somente como o Tribunal de Contas da União e o Poder Judiciário. Isto porque envolve problemas complexos, dados sociais, econômicos e políticos; deveria usar recursos, inclusive financeiros, mediante os quais tal Casa dispõe, com o fim de encarregar terceiros para efetuar pesquisas, tal como as Universidades.

Em contrapartida, na Câmara dos Deputados existem sete projetos autorizando a desaposentação. A Comissão de Seguridade Social da Câmara aprovou projeto de lei (PL 3.884/08) do deputado Cleber Verde, contudo, na justificativa do projeto, a aprovação pelo Judiciário ainda marcou a principal premissa para a criação de tal direito (BRASIL, 2008).

Nesse passo, deve haver a indução de pesquisas e projetos interdisciplinares sobre o tema evitando-se que o Judiciário ocupe lacunas deixadas pelas instancias politicas tradicionais. Deve-se deslocar o eixo da pesquisa acadêmica brasileira, resgatando a importância da produção de dados para a argumentação jurídico-política inerente ao processo de elaboração normativa. Com essa ressignificação, se ressaltara o papel contemporâneo do instrumento normativo por meio da relevância à chamada "avaliação legislativa".

Outro exemplo é o Projeto de Lei ${ }^{\circ}$. 1.168/ 2011 do deputado Marco Aurélio Ubiali do PSB-SP. Contudo, mais uma vez, na defesa do projeto, pouco se nota o levantamento de 
impressões e opiniões dos diversos atores sociais envolvidos na interpretação e aplicação das normas, em contrapartida, a esfera judicial é ressaltada de forma paternal. (BRASIL, 2011)

Percebe-se que o Poder legislativo não esta fazendo a devida avaliação do ciclo de vida da futura lei de desaposentação. Ate agora, não houve naquele Poder audiências publicas sobre o tema para que se ouçam os diferentes setores da sociedade, sobretudo, as Universidades. Não se percebe, claramente dos discursos dos criadores dos projetos quem são o que dizem e argumentam "pessoas que entendem de Previdência e defesa dos direitos dos aposentados". Ainda é tímida a produção cientifica que envolve todo o processo de criação da norma de desaposentação.

Apesar do desempenho fraco na produção de bons argumentos teóricos para a construção da lei, a desaposentação torna-se instrumento cada vez mais conhecido pela população. Isto porque, já está sendo disseminado pelas mídias que por meio desse mecanismo, o aposentado que retornou ao mercado de trabalho renuncia ao benefício pago pelo INSS e pede o recálculo da aposentadoria, incorporando as contribuições e o tempo de serviço acumulados com o novo trabalho. O objetivo é conseguir uma aposentadoria maior.

Entretanto, a construção da norma sobre o tema não esta passando por uma profunda criação de argumentos sólidos na construção da referida lei. Assim, tal qual no caso da desaposentação, se almeja a criação de projetos nos setores competentes do Parlamento brasileiro para estudos de criação de normas; acompanhamento do processo legislativo e a produção de pareceres sobre as proposições legislativas, tudo necessários ao debate legislativo.

Assim sendo, ao Poder Judiciário deveria caber, nesse modelo, o controle jurídico da atividade intervencionista dos demais Poderes. Contudo, com a não ocorrência do proposto acima, sobre ele também recaem as expectativas e pressões da sociedade no sentido da mais célere possível busca dos fins da Constituição, incluindo a imediata fruição de direitos sociais ou a extensão de benefícios.

\section{O ATIVISMO JUDICIAL E ATUAÇÃO DEFICIENTE DO PODER LEGISLATIVO}

Keenan D. Kmiec (2004), autor que comentou artigo do criador da expressão “ativismo Judicial” (judicial activism), de início, afirma que há uma imprecisão terminológica não deixando claro quanto a ser algo positivo ou negativo. 
Segundo Keenam D. Kmiec (2004) a expressão foi usada pela primeira vez pelo historiador Arthur Schlesinger Jr., no ano de 1947, em matéria sua publicada na revista estadunidense Fortune. Trata-se de uma revista não jurídica (leiga), de atualidades norteamericanas, ressaltada por Paulo Gustavo Gonet Branco (2011, p. 369) “[...] entre propaganda de Whisky e Aqua Velva".

O próprio criador da expressão judicial activism, o já mencionado historiador Arthur Schlesinger Jr., no seu texto famoso, divulgou o enunciado ativismo separando os juízes da Corte Americana em dois grupos. Uns comprometidos com a promoção do bem-estar social (Hugo Black, William O. Douglas, Frank Murphy e Wiley Rutlege), outros (Felix Frankfurter, Harold Burton e Robert H. Jackson) defendiam que objetivos sociais deveriam ser alcançados por outros Poderes são os chamados campeões de "autocontenção" (selfrestraint). Problema lançado, pois se criou imprecisão tanto terminológica do termo quanto a ser positivo ou negativo. Não menos conflitos interiores que o ativismo judicial acaba criando (KMIEC, 2004).

Outro aspecto importante do ativismo judicial notado por Schlesinger foi que o raciocínio jurídico era dotado de rasa cientificidade. Os juízes campeões de promoção de bem estar social (judicial activists) anotavam como indissociáveis Direito e Política. Portanto, não haveria uma resposta correta de pronto, pois decisão judicial implicaria numa escolha política do julgador. Com está visão, os tidos como “campeões de autocomedimento" teriam uma ilusória pretensão de objetividade no ato decisório, postura desmedida para o senso de justiça e a necessidade por criar melhoras sociais que devem nortear o julgador. (KMIEC, 2004, p. 1446).

O que se observa é que o famoso texto de Schlesinger não deixa nítido qual a melhor postura da expressão: se em âmbito politico ou jurídico. Ressalva Kmiec (2004, p. 14631476) que o artigo de cinco páginas dividindo ideologicamente os membros da Suprema Corte Americana naquela época produziu fôlego em solo estadunidense e passou a representar a defesa em juízo de ações que politicamente não se mostravam suficiente.

Para aquecer tal debate Kiemic (2004) afirmava que as dúvidas existentes quanto ao fim positivo ou negativo da expressão ensejou, por exemplo, reflexões sobre: i) Juízes eleitos vs. Leis democraticamente aprovadas; ii) Política vs. Direito; iii) direitos humanos vs. Supremacia popular; iv) uso criativo de precedentes vs. uso estrito de precedentes; v) decisões orientadas politicamente vs. decisões orientadas juridicamente. 
Já no Brasil, cria-se um contexto que permite compreender a transposição de um Estado Legislativo de Direito, com grande formalismo do positivismo, para um com aspectos pós-positivistas e neoconstitucionalista. É o chamado Estado Constitucional de Direito.

Barroso (2007) aponta três marcos para o novo direito constitucional: um histórico, um filosófico e outro teórico. Quanto a este, três grandes transformações o constituem: o reconhecimento da forca normativa da Constituição, a expansão da jurisdição constitucional e o desenvolvimento de uma nova dogmática da interpretação constitucional. No marco filosófico, estão pós-positivismo e, por fim, no teórico, está o constitucionalismo pós-guerra, na Europa Continental, e no Brasil, por sua vez, o papel da Constituição de 1988 e o processo de redemocratização que a mesma ajudou a protagonizar.

Outro fator de impulsão do ativismo judicial, no Brasil, dá-se em face do modelo de Estado interventor. Para Ramos (2010, p. 268-271) trata-se de um Estado que o constitucionalismo pátrio vem dando prestígio desde a Constituição de 1934: "o do Estado democrático-social, de perfil intervencionista”.

Ao Poder Judiciário, diante de tal modelo intervencionista, caberia o controle jurídico da atividade intervencionista dos demais poderes. Contudo, sobre ele, também recaem tantos as expectativas quanto às pressões da sociedade no sentido da maneira mais célere possível da consecução dos fins traçados pela Constituição, tais como a imediata fruição dos direitos sociais, extensão progressiva e universal de benefícios concedidos a determinadas categorias ou regiões com a exclusão de outras.

Outro fator de impulsão do ativismo judicial, no Brasil, segundo Ramos (2010, p. 278) advém da expansão do controle abstrato de normas. Contudo, elenca que o manejo do controle de constitucionalidade em sede concentrada ou técnica do controle abstrato tende a refluir na medida em que o tempo passa. A descoberta desse instrumental, relativamente recente no constitucionalismo brasileiro, tende a provocar certo "deslumbramento" em Cortes constitucionais jovens ou em tribunais consagrados, que passam a exercer mais intensamente o controle de constitucionalidade.

Pode ainda pertencer aos fatores de impulsão à ênfase do papel político desenvolvido pelo Poder Judiciário. Agora, o Judiciário passa a assumir atividades antes restritas ao Poder Legislativo e Poder Executivo. É o fenômeno de politização em que tal Poder recebe atribuições das normas constitucionais para influir na concretização e determinação da política governamental. 
Perez (2012, p. 132-140) exemplifica as causas da inoperância do Legislativo: crise da partidária, inaptidão do parlamentar para concretizar a vontade geral; morosidade do processo legislativo; desvalorização da lei, dentre outros. Com tais exemplificações é partidário da ideia de que tal falta de desempenho ou inexecução ineficiente do Legislativo acarreta ao crescente incremento do ativismo judicial.

Appio (2012, p. 72) defende a representatividade eleitoral ainda como um importante fator de contenção judicial. Para o autor, o Poder Legislativo imporia limites políticos ao decisionismo judiciário resultando num equilíbrio de forças. Contudo, diante da sociedade brasileira, um tanto quanto fragmentada, há uma tendência espontânea em concentrar no Poder Judiciário todas as expectativas no que se refere à manutenção do regime democrático e das garantias individuais, "através de verdadeira divinização das concepções morais e filosóficas dos juízes constitucionais".

Com tudo isto, se percebe uma inversão. Caberia ao Poder Legislativo articular-se por meio de uma avaliação legislativa colocando-se sob o foco os efeitos reais ou potenciais que resultam da aplicação de uma norma. Isto porque no universo jurídico existe a limitação do debate. Importante assinalar que a função judicante priva uma discussão mais ampla, pois exclui dela o não técnico.

A discricionariedade legislativa traçada pelo declínio do sistema representativo e mau funcionamento do Poder Legislativo levou a apropriação judicial da função normativa. Em contrapartida, o cenário desenhado seria apagado caso os parlamentares conseguissem atender as necessidades legislativas atuais gerando em tempo hábil as leis reclamadas pela sociedade.

\subsection{O ativismo judicial e a discricionariedade do Legislativo}

O Legislador produz textos revertidos de validade jurídica não submetendo esta produção a crivos de racionalidade e coerência sistemática. A atuação politica é no seu predominante, circunstancial, submetida a pressões sociais e voltada para o contingente e episódico, normalmente. O mesmo se pode atribuir ao administrador e aos agentes econômicos (PASSOS, 2013, p. 612).

Assim, ordenamento é o texto que resulta da linguagem criativa das autoridades, que são plurais e muitas vezes sem contato entre si. É um texto submetido à motorização e a pressa. Sua linguagem é deficiente e necessitada de uma reelaboração reflexiva que ponha 
este material diversificado em uma ordem acabada. "Isto é precisamente o sistema, a construção do ordenamento em `linguagem cientifica’” (ROBLES, 1988, p. 15).

O que existe no ordenamento jurídico é o texto jurídico em bruto, que foi produzido sob a pressão dos fatos políticos, econômicos etc., assim, é esse texto bruto que será submetido ao refinamento e reelaboração pela ciência do direito, gerando um novo texto que resulta do primeiro. Nessa perspectiva, acaba caindo aos julgadores um esforço no sentido de emprestar coerência, previsibilidade e consistência ao que deveria estar em seu estado bruto. Isso tudo, quando há lei. Quando esta se faz ausente, ou quanto está em seu processo de criação, ainda assim, acaba-se legitimando aos juízes as necessidades, ônus, aspirações e solicitações quotidianas dos membros da sociedade.

Questiona Appio (2012, p. 72) que a representatividade eleitoral ainda se apresenta como um importante fator de contenção judicial. Para o autor, o Poder Legislativo imporia limites políticos ao decisionismo judiciário resultando num equilíbrio de forcas. Contudo, diante da sociedade brasileira, um tanto quanto fragmentada, há uma tendência espontânea em concentrar no Poder Judiciário todas as expectativas no que se refere à manutenção do regime democrático e das garantias individuais, "através de verdadeira divinização das concepções morais e filosóficas dos juízes constitucionais".

Tanto é assim, que o deputado, Sr. Arnaldo Faria De Sá do PTB-SP, em seu discurso na Tribuna da Câmara dos Deputados, felicita a atuação do Superior Tribunal de Justiça, mas ainda critica a demora no julgamento pelo Supremo Tribunal Federal (BRASIL, 2013a).

Em outra postura do Poder Legislativo sobre o tema, nota-se que caberia ao referido Poder dar ênfase a construção de um programa de qualidade da produção normativa, baseado em checklist de referência a ser observado antes da tomada de decisões regulatórias. Contudo, quedou-se ao Judiciário, perito em todos os assuntos, o elemento mais importante, conforme o discurso do deputado federal Sr. Arnaldo Faria de Sá do PTB-SP. Para o parlamentar, a deferência do assunto pela Procuradoria- Geral da República e vertente de grande injustiça referente ao fator previdenciário são fundamentais para a aprovação da desaposentação (BRASIL, 2014).

A importância dada ao Judiciário é tamanha que mais uma vez as decisões deste Poder sobre a desaposentação é muito mais importante do que uma serie de análises baseadas no emprego de métodos científicos, no que tange à execução e os efeitos dos atos legislativos, é o que se depreende mais uma vez do discurso do parlamentar, o Sr. Arnaldo Faria de Sá: 
Aguardo também, ansiosamente, a decisão do Supremo Tribunal Federal sobre questão da desaposentação.[...]. Por isso, nos dias 12 e 13 de maio, a COBAP Confederação Brasileira de Aposentados, Pensionistas e Idosos e a Federação de Aposentados de São Paulo estarão nesta Casa cobrando o projeto que trata da recomposição das perdas. É lamentável como esta Casa trata aposentado e pensionista. Isso não pode continuar acontecendo (BRASIL, 2014).

Com tudo isto, percebe-se uma inversão. Caberia ao Poder Legislativo articular-se por meio de uma avaliação legislativa colocando-se sob o foco os efeitos reais ou potenciais que resultam da aplicação de uma norma. Isto porque no universo jurídico existe a limitação do debate. Importante assinalar que a função judicante priva uma discussão mais ampla, pois exclui dela o não técnico. No dizer de Barroso (2007, p. 14), há "o perigo de se produzir uma apatia nas forcas sociais, que passariam a ficar à espera de juízes providenciais".

Percebe-se que a discricionariedade legislativa, traçada pelo declínio do sistema representativo e mau funcionamento do Poder Legislativo levou a apropriação judicial da função normativa. Em contrapartida, o cenário desenhado seria apagado caso os parlamentares conseguissem atender as necessidades legislativas atuais gerando em tempo hábil as leis reclamadas pela sociedade.

Importante seria que os projetos de leis perpassassem por um emprego de métodos científicos relacionados à execução e os efeitos dos atos legislativos. Enfim, se colocaria sob o foco os efeitos reais ou potenciais que resultam da aplicação de uma norma. Prever e avaliar a adequação de potenciais efeitos de determinada alteração legislativa ou examinar os eventuais efeitos reais produzidos pela inovação legal.

A ideia é expurgar a discricionariedade legislativa com um forte toque de adoção de medidas de planejamento e revisão legislativa. A proposta é adotar um programa de qualidade de produção normativa inspirado em um checklist de referência a ser observado antes da tomada de decisões regulatórias por parte do próprio parlamento.

Contudo, no que pese ao caso da desaposentação, diante da atuação deficiente do Poder Legislativo acabou por construir jurisprudência consolidada do Superior Tribunal de Justiça (REsp nº1334488/SC). Trata-se de decisão que antecipou a criação de política legislativa e executiva sobre o direito fundamental à aposentadoria.

Exerceu-se um ativismo judicial que não se confunde com arbitrariedade, tampouco com temas correlatos à tripartição dos poderes e ao princípio democrático. Tal pensamento fica claro ao se perceber que a atuação jurisdicional constitucional não se efetiva exclusivamente por vontade do órgão jurisdicional. O STJ seguiu o mandamento 
constitucional da inércia cujo princípio pede que a atuação do Judiciário ao exercer a jurisdição, só será exercido quando ele for provocado.

Uma vez provocado, o Tribunal analisou o caso, conforme determina o princípio da inafastabilidade do Judiciário, o que culmina no direito fundamental de acesso à Justiça, nos moldes do artigo $5^{\circ}$, inciso XXXV, da CF/88.

\section{CONSIDERAÇÕES FINAIS}

É um dos pressupostos das sociedades modernas que a produção de conhecimento mais rigoroso sobre a realidade pode ajudar a transformá-la, de preferência para bem melhor. Trata-se da relação entre ciência e politica.

Assim, no processo criativo da lei deve haver a participação das Universidades como monitoramento e avaliação dos resultados. A par disso, cabe ao parlamento, como setor que dispõe de maiores instrumentos que não estão disponíveis aos tribunais, com o auxilio de tais Universidades, detectar como uma norma pode influenciar ou impactar a outra e vice-versa, assim como, a qualidade e a eficiência da norma no processo de implementação e consolidação de determinada diretriz.

Percebe-se dos projetos de Lei sobre Desaposentação, que não há monitoramento, avaliação de resultados, influencia com os diversos ramos da ciência, qualidade e eficiência da norma a ser criada, muito menos, a participação das Universidades nesse debate. Percebese que o Poder Legislativo espera exaurir os instrumentos jurídicos disponíveis para concretizar a Constituição e assegurar o gozo dos direitos dos cidadãos.

Diante da falta de desempenho do Poder Legislativo, aqui configurada pela tímida construção de parcerias para a configuração de uma eficiente avaliação legislativa, no Brasil, concretiza-se a ocupação desta lacuna pelo Poder Judiciário.

A construção de uma verdadeira política legislativa, instituída como política pública que envolva o conhecimento Universitário de impactos de alterações legislativas, bem como de promoção da participação social e da democratização do processo de elaboração normativa, deve ser de vital iniciativa a ser promovida pelo Estado brasileiro.

Deve ser cada vez mais estimulado a construção de parcerias e pela promoção do diálogo com a comunidade internacional, incentivando diversas formas de cooperação que permitam o contínuo aprimoramento das instituições democráticas na construção de leis. Assim como, a construção de projetos que cooperem e viabilizem internalização das boas práticas no ciclo de vida da lei. 
De outro lado, tão importante se faz o debate sobre reformas institucionais no âmbito dos juristas brasileiros. Dessa forma, ainda é escassa, no Brasil, literatura jurídica voltada à relação entre o direito e o desenvolvimento econômico, político e social.

Assim sendo, quando se voltam a uma ciência de criação de leis, gestores públicos e parlamentares ainda possuem certa dificuldade em encontrar referências acadêmicas para informar o debate que pretendem construir. Essa dificuldade de interlocução entre, de um lado, parlamentares e, de outro, professores e pesquisadores, está relacionada com diversos obstáculos.

A par disso, deve-se criar no ambiente Universitário a sua efetiva participação no processo criativo da lei não com serviço de parecer jurídico, consultoria, ou mesmo pesquisas interessadas. Mas pesquisas e trabalhos universitários que abram espaço para a reflexão de um projeto de lei que atenderá os fins sociais.

Sendo assim, deve haver, na construção da lei, a fluência de ideias entre o Congresso Nacional e outros setores de produção de conhecimento, como a comunidade de juristas, de médicos, sociólogos, economistas que podem desempenhar papel de enorme destaque na produção normativa nacional.

Por fim, mas não menos importante, o próprio processo legislativo acaba sendo um desconhecido da Universidade jurídica no Brasil. Assim como no contrato de adesão, na qual as clausulas não são discutidas, também a lei é tomada como algo dado, acabado e que deverá ser cumprido. Ao mesmo tempo, são escassas as obras jurídicas tendo por tema o próprio processo legislativo.

O presente estudo não trouxe medidas concretas, ou seja, certos princípios básicos que levem ao Legislativo fazer uma produção normativa de qualidade. Muito menos esgota o tema. Mas, lança reflexões para a construção de um processo avaliativo de qualidade com participação das Universidades. Com a realização deste trabalho qualitativo o Judiciário poderá não ter mais feições de um gigante solucionador de conflitos atribuídos constitucionalmente a outros Poderes. 


\section{REFERÊNCIAS}

ALMEIDA, Guilherme Alberto Almeida de; PAULA, Felipe de. Avaliação Legislativa e Projeto Pensando o Direito: uma afortunada aproximação. Serie Pensando o Direito. Brasília: Ministério da Justiça, v 50, p 25-37. 2013.

APPIO, Eduardo.O controle judicial de políticas públicas no Brasil. 5a reimp. Curitiba: Juruá, 2012.

BARROSO, Luis Roberto. Neoconstitucionalismo e constitucionalização do direito (o triunfo tardio do direito constitucional no Brasil). Revista Eletrônica sobre a reforma do Estado (RERE). n. 9. Salvador: Instituto Brasileiro de Direito Público, mar.-maio, 2007.

BARROSO, Odúlia Capelo. A técnica Legislativa face à lei complementar nº. 95, de 26 de fevereiro de 1988. 2008, 43p. Monografia (Programa de Pos-Graduação)- Câmara dos Deputados, Curso de Formação, Treinamento e Aperfeiçoamento, Brasilia, 2008.

BRASIL. Assembleia Legislativa do Maranhão. Portal Atividade Legislativa. Disponível em: http://www.al.ma.leg.br/. Acesso em: 09 de jul de 2014.

Câmara dos Deputados. Discursos e notas taquigráficas. Publicado em 24 mar 2013a. Disponível em: http://www.camara.leg.br. Acesso em: 22 set 2016.

. Câmara dos Deputados. Trabalho e previdência. STF decidirá validade de desaposentação; deputado defende medida. Publicado em 20 out. 2014. Disponível em: http://www.camara.leg.br. Acesso em: 22 set 2016.

Decreto n 3.048 de 06 de maio de 1999. Aprova o Regulamenta da Previdência Social, e dá outras providências. Diário Oficial [da] República Federativa do Brasil, Poder Executivo, Brasília, DF, Seção 1 de 7 de maio de 1999a, Página 50. Disponível em: http://www.planalto.gov.br/ccivil_03/decreto/d3048.htm. Acesso em: 22 set 2016. 
Lei Complementar n. ${ }^{\text {95/98 de }} 26$ de fevereiro de 1998. Dispõe sobre a elaboração, a redação, a alteração e a consolidação das leis, conforme determina o parágrafo único do art. 59 da Constituição Federal, e estabelece normas para a consolidação dos atos normativos que menciona. Disponível em: http://www.planalto.gov.br/ccivil_03/leis/lcp/lcp95.htm. Acesso em: 10 de jul de 2014.

Ministério da Justiça. Secretaria de Assuntos Legislativos. O papel da pesquisa política legislativa: metodologia e relato de experiências do Projeto Pensando o Direito. Série Pensando o Direito, 50. Brasília: Ministério da Justiça, 2013b.130 p.

Presidência da Republica. Mensagem de Veto $n^{\circ}$ 16, de 11 de janeiro de 2008. Disponível em: http://www2.planalto.gov.br/presidencia/legislacao. Acesso em: 10 de jul de 2014.

Senado Federal. Projeto de Lei do Senado n ${ }^{\circ}$ 91/2010. Acrescenta $\S 9^{\circ}$ e $\S 10^{\circ}$ ao art. 57, da Lei $\mathrm{n}^{\circ}$ 8.213, de 24 de julho de 1991 (permite a renúncia do benefício da aposentadoria; prevê a possibilidade de solicitação de aposentadoria com fundamento em nova contagem de tempo de contribuição). Senador Paulo Paim. Disponível em: http://www.senado.gov.br. Acesso em: 22 set 2016.

Superior Tribunal de Justiça. Recurso Especial $\mathrm{n}^{\circ}$.1334488-SC, Rel. Min. Herman Benjamin. Primeira Seção. Julgado em 08 de maio de 2013. Diário de Justiça Eletrônico de 14 de maio de 2013. RSTJ vol. 230 p. 400. RT vol. 936 p. 350.Disponível em: http://www.stj.jus.br/SCON/jurisprudencia/doc.jsp?processo=1334488\&\&b=ACOR\&p=true \&t=J URIDICO\&l=10\&i=3. Acesso em: 20 set. 2015.

BUCCI, Maria Paula Dallari. Direito Administrativo e Políticas Públicas. São Paulo: Saraiva, 2002.

DWORKIN, Ronald. O império do Direito. São Paulo: Martins Fontes, 2007.

FERREIRA FILHO, Manoel Gonçalves. Do processo legislativo. 6 ed. São Paulo: Saraiva, 2009. 
FISHER, Louis. Constitutional Dialogues: interpretation as political process. [S.1.]: Princeton Univ. Press, 1988.

GARAPON, Antonie. O guardador de promessas: justiça e democracia. Lisboa: Instituto Piaget, 1964.

HABER, Carolina Dzimidas. A Relação entre o Direito e a Política no Processo Legislativo Penal, 2011. Tese (Doutorado) - Departamento de Filosofia do Direito da Universidade de São Paulo, São Paulo, 2011.

IBRAHIM, Fábio Zambitte. Curso de Direito Previdenciário. 12 ed. Rio de Janeiro. Impetus, 2011.

KMIEC, Keenan D. The Origin and Current Meaning of "Judicial Activism". California Law Review, v. 92, n. 5. 2004, p. 1441-1477.

MADER, Luzius. Avaliação Prospectiva e Análise de Impacto Legislativo Tornam as Leis Melhores? Cadernos de Ciência da Legislação, Oeiras, Portugal, nº 42/43, p. 177-191, janjun 2006.

MENEGUIM, Fernando. Avaliação de Impacto Legislativo no Brasil. [Brasília]: Centro de Estudos da Consultoria do Senado: mar 2010. (textos para discussão, 70)

OLIVEIRA, Antônio Flávio de, Processo legislativo, doutrina e academia: hipóteses de afastamento e efeitos deletérios. Fórum Administrativo: Direito Público, Belo Horizonte, v. 10, n 116 , p. 67-75, out. 2010. Disponível em: <http://bdjur.stj.jus.br/dspace/handle/2011/34560>. Acesso em. 09 de jul de 2014.

PASSOS, J. J. Calmon de. O Magistrado, Protagonista do Processo Jurisdicional? In: DIDIER, Fredie Jr. et al. (Coord.), Ativismo Judicial e Garantismo Processual. Salvador: Editora Juspodivm, 2013. 
PEREZ, Carlos Alberto Navarro. Relação entre o Ativismo Judicial e a Atuação Deficiente do Poder Legislativo. Altruismo a desserviço da democracia. Revista de Direito Constitucional e Internacional. São Paulo, ano 20, v. 78, jan.-mar./2012.

RAMOS, Elival da Silva. Ativismo Judicial- Parametros dogmáticos. São Paulo: Saraiva, 2010.

ROBLES, Gregório. Cuatro Estúdios de Teoria Comunicacional del Derecho. Madrid: Civitas, 1988.

RUA, Maria das Graças. Avaliação de Políticas, Programas e Projetos. [S.1]: ENAP, 2003. Mimeografado.

SAYEG, Ricardo; BALERA, Wagner. O capitalismo humanista. Petropolis: KBR, 2011. 